\title{
Dehydration of xylose to furfural using a Lewis or Brönsted acid catalyst and $\mathrm{N}_{2}$ stripping
}

\author{
Iker AGIRREZABAL-TELLERIA ${ }^{\mathrm{a}, *}$, Cristina GARCÍA-SANCHO b, Pedro MAIRELES-TORRES b, \\ Pedro Luis ARIAS a \\ a Department of Chemical and Environmental Engineering, Engineering School, University of the Basque Country (EHU/UPV), Alameda Urquijo s/n, \\ 48013, Bilbao, Spain \\ ${ }^{\mathrm{b}}$ Department of Inorganic Chemistry, Cristallography and Mineralogy (Unit Associated to ICP-CSIC), Science Faculty, University of Málaga, Campus \\ Teatinos s/n, 29071, Málaga, Spain
}

A R T I C L E I N F

Article history:

Received 24 February 2013

Accepted 1 April 2013

Published 20 July 2013

\section{Keywords:}

Lewis acid

Brönsted acid

Reaction mechanism

Xylose dehydration

Furfural

Nitrogen stripping

\section{A B S T R A C T}

The activity of Lewis $\left(\mathrm{Nb}_{2} \mathrm{O}_{5}\right)$ and Brönsted (Amberlyst 70 ) acid catalysts for the cyclodehydration of xylose to furfural was studied. The nature of the acidity resulted in significant changes in the reaction mechanism. Lewis acid sites promote the formation of xylulose, while Brönsted acid sites are required to further dehydrate the sugar to furfural. Amberlyst 70 in water/toluene at $175{ }^{\circ} \mathrm{C}$ showed lower activity but gave a higher furfural yield. Using $\mathrm{N}_{2}$ as the stripping agent considerably improved the furfural yield and product purity in the stripped stream. Catalyst stability was also studied.

(C) 2013, Dalian Institute of Chemical Physics, Chinese Academy of Sciences. Published by Elsevier B.V. All rights reserved.

\section{Introduction}

Among the furan-based compounds, furfural (FUR) is one of the most interesting building-blocks to produce high added-value compounds. It is also used as an industrial solvent [1]. FUR is produced from pentosan-rich biomass by xylose cyclodehydration [2]. Current FUR production uses homogeneous catalysts, which lead to corrosion and toxic effluent issues as well as high separation and purification costs. Furfural condensation reactions that produce fragments and intermediates (rate constant $k_{2}^{\prime}$ ) and resinification reactions (rate constant $k^{\prime}{ }_{3}$ ) occurring in the aqueous phase (Scheme 1(a)) can be largely avoided by using steam as a stripping agent [3].

Novel heterogeneous catalysts that have been used in water or toluene include functionalized mesoporous supports [4-6], metal oxides [7], and zeolites [8,9]. Strong acid sites supported on materials that have suitable pore arrangements are essential to achieve high xylose conversion and FUR selectivity. Catalysts such as functionalized SBA-15 can give high FUR yields by the tuning of the pore structure [10] and Lewis/Brönsted ratio [11-13]. A drawback in the industrial use of these systems is that the biphasic process needs extra solvent/FUR separation stages, which is still a problem even if greener solvents than toluene are used [14]. For this reason, a novel separation technique using $\mathrm{N}_{2}$ as the stripping agent [15] in combination with the use of a solid heterogeneous catalyst was studied here.

This work evaluated the use of solid heterogeneous Lewis and Brönsted acid catalysts in xylose dehydration in water as

\footnotetext{
* Corresponding author. Tel: +34-617912295; Fax:+34-946014179; E-mail: iker.aguirrezabal@ehu.es DOI: 10.1016/S1872-2067(12)60599-3 | http://www.sciencedirect.com/science/journal/18722067 | Chin. J. Catal., Vol. 34, No. 7, July 2013
} 
the solvent together with the use of $\mathrm{N}_{2}$ stripping. Amberlyst 70 (A70) was selected as a representative Brönsted acid catalyst and niobium pentoxide $\left(\mathrm{Nb}_{2} \mathrm{O}_{5}\right)$ on a mesoporous silica Cabosil named as $\mathrm{Nb} / \mathrm{Cab}$ was the Lewis acid. The catalysts showed high activity and recyclability in transesterification reactions [16] and the dehydration of 5-hydroxymethyl-2-furaldehyde (HMF) from fructose [17]. The use of a combination of catalysts containing different acid types and a novel process engineering has interesting potential. The hydrothermal stability and regenerability of $\mathrm{Nb} / \mathrm{Cab}$ were also studied.

\section{Experimental}

$\mathrm{Nb} / \mathrm{Cab}$ was prepared by incipient wetness impregnation using an aqueous solution of niobium oxalate in $0.1 \mathrm{~mol} / \mathrm{L} \mathrm{ox}-$ alic acid (12 wt\%), dried in air at $60^{\circ} \mathrm{C}$ and calcined at $550{ }^{\circ} \mathrm{C}$ for $6 \mathrm{~h}$. Amberlyst 70 was supplied by Dow Chemicals.

$\mathrm{N}_{2}$ isotherms of the catalysts were obtained at $-196^{\circ} \mathrm{C}$ using an Autosorb 1C (Quantachrome) apparatus. Samples were first degassed at $150{ }^{\circ} \mathrm{C}$ for $12 \mathrm{~h}$. The specific surface area $\left(A_{\mathrm{BET}}\right)$ was calculated using BET method, and the micropore volume was estimated by the $t$-plot method. Temperature-programmed desorption of ammonia ( $\mathrm{NH}_{3}$-TPD) was carried out as follows. The sample $(0.2 \mathrm{~g})$ was first heated under $\mathrm{N}_{2}$ to $300{ }^{\circ} \mathrm{C}$ and then exposed to $\mathrm{NH}_{3}$ at $120{ }^{\circ} \mathrm{C}$. After flushing off excess $\mathrm{NH}_{3}$ at 120 ${ }^{\circ} \mathrm{C}$ with $\mathrm{N}_{2}$ for $1 \mathrm{~h}$ and cooling to $80{ }^{\circ} \mathrm{C}$, the TPD program was performed $\left(10{ }^{\circ} \mathrm{C} / \mathrm{min}\right.$ to $500{ }^{\circ} \mathrm{C}$ and kept for $\left.30 \mathrm{~min}\right)$. Desorbed $\mathrm{NH}_{3}$ was monitored by a TCD in an online gas chromatograph (Shimadzu GC-14A). Fourier transform infrared (FT-IR) spectra of adsorbed pyridine were recorded on a Shimadzu FT-IR instrument (FTIR 8300) using self supported wafers of $15 \mathrm{mg} / \mathrm{cm}^{2}$ placed in a vacuum cell with greaseless stopcocks and $\mathrm{CaF}_{2}$ windows. The sample was evacuated at 250 ${ }^{\circ} \mathrm{C}$ and $0.01 \mathrm{~Pa}$ overnight, exposed to pyridine at room temperature for $15 \mathrm{~min}$, and outgassed at $200{ }^{\circ} \mathrm{C}$.

Xylose dehydration batch reactor tests were performed in a $200 \mathrm{ml}$ stainless steel reactor. The $\mathrm{N}_{2}$ stripping tests were performed in a $2 \mathrm{~L}$ reactor. In a typical $\mathrm{N}_{2}$ stripping test at $175^{\circ} \mathrm{C}$ and $800 \mathrm{kPa}$, the reactor was first loaded with the catalyst and water. After heating, the xylose solution was fed from a $\mathrm{N}_{2}$ pressurized vessel (to reach initial xylose load of $1 \mathrm{wt} \%$ ). $\mathrm{N}_{2}$ at room temperature was bubbled into the liquid from the bottom at $150 \mathrm{ml} / \mathrm{min}$. Stripped vapor containing FUR was condensed and separated from the stripping agent $\left(\mathrm{N}_{2}\right)$. Samples were taken at different intervals until the condensate was $80 \%$ of the initial reactor volume.

The products and remaining xylose were quantified using an HPLC module ICS-3000 from DIONEX coupled to an AS40 Autosampler. FUR was quantified after separation using a Kinetex C18-XB $150 \mathrm{~mm} \times 4.6 \mathrm{~mm}$ column from Phenomenex kept at $40{ }^{\circ} \mathrm{C}$. A UV-2070 Plus detector from JASCO at $280 \mathrm{~nm}$ wavelength was used. The mobile phase consisted of $\mathrm{H}_{2} \mathrm{SO}_{4}$ $(0.01 \mathrm{~mol} / \mathrm{L})$ and acetonitrile aqueous solution $(10 \%, \mathrm{v} / \mathrm{v})$ at a flow rate of $1 \mathrm{ml} / \mathrm{min}$. Xylose was quantified after separation using a CarboPac PA20 $3 \mathrm{~mm} \times 150 \mathrm{~mm}$ column at $30{ }^{\circ} \mathrm{C}$ with $0.5 \mathrm{ml} / \mathrm{min}$ of $\mathrm{NaOH}(8 \mathrm{mmol} / \mathrm{L})$ as the mobile phase. Detection was performed using an electrochemical cell with integrated amperometry, and the standard Carbohydrate Quad method was used.

The xylose conversion was measured at different intervals. FUR yield was calculated as mole of FUR obtained per mole of converted xylose.

\section{Results and discussion}

From the characterization by $\mathrm{N}_{2}$ physisorption, $\mathrm{Nb} / \mathrm{Cab}$ has a specific surface area of $169 \mathrm{~m}^{2} / \mathrm{g}$. Nb/Cab and A70 have low crystallinity (checked by XRD). The FT-IR spectra of pyridine saturated samples are shown in Fig. 1(a). The $\mathrm{Nb} / \mathrm{Cab}$ sample showed only a Lewis site band at $1446 \mathrm{~cm}^{-1}$, while the A70 showed only Brönsted sites at $1548 \mathrm{~cm}^{-1}$. The peak at 1490 $\mathrm{cm}^{-1}$ is due to both Lewis and Brönsted acid sites. The acidity data measured by $\mathrm{NH}_{3}$-TPD showed significant differences in the acid site amounts, of 2.55 and $0.045 \mathrm{mmol} / \mathrm{g}$ for A70 and $\mathrm{Nb} / \mathrm{Cab}$, respectively. The $\mathrm{N}_{2} \mathrm{O}_{5}$ content was $12 \mathrm{wt} \%$, as determined by X-ray fluorescence spectroscopy.

The nature of the acid sites and strength determine xylose dehydration activity and furfural yield [12]. The batch reactor xylose dehydration catalytic tests at $175{ }^{\circ} \mathrm{C}$ (Batch W) showed that the Lewis sites gave a higher initial xylose conversion. Even with the two catalysts present with different total acid amounts, the xylose molecule was more easily adsorbed on the
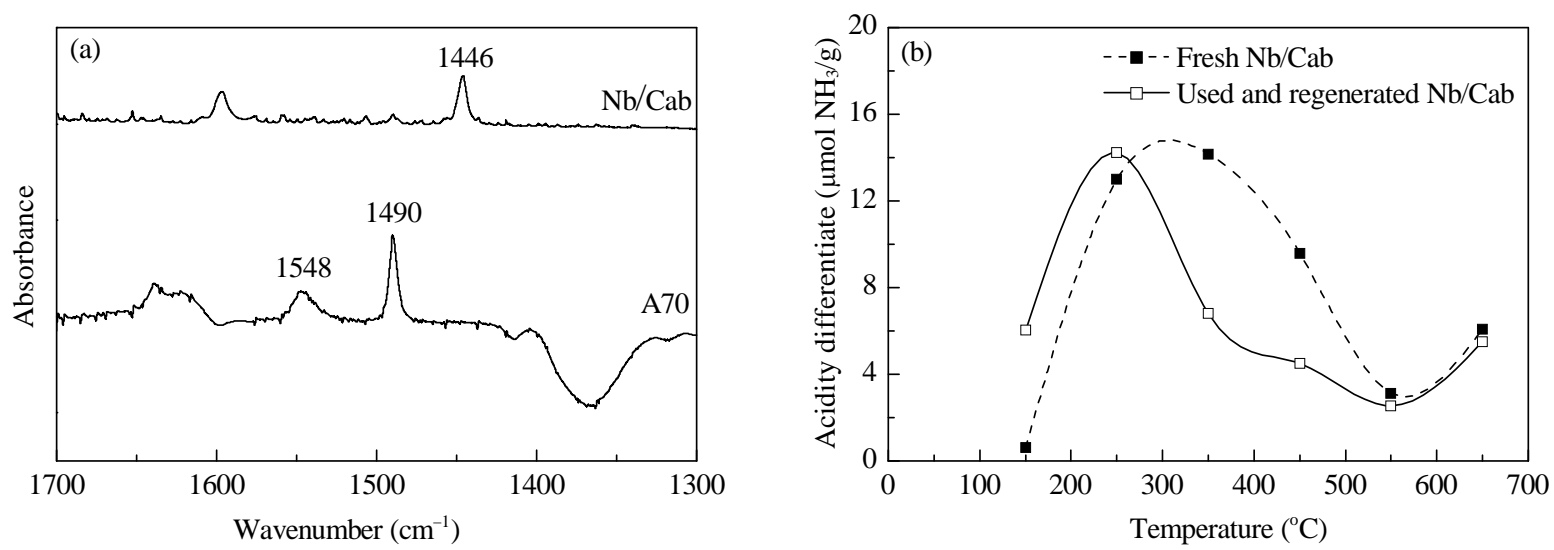

Fig. 1. (a) Acid site characterization of Amberlyst 70 (A70) and $\mathrm{Nb}_{2} \mathrm{O}_{5}$ on mesoporous silica cabosil (Nb/Cab) by pyridine-FTIR; (b) NH${ }_{3}-\mathrm{TPD}$ profiles of $\mathrm{Nb} / \mathrm{Cab}$. 

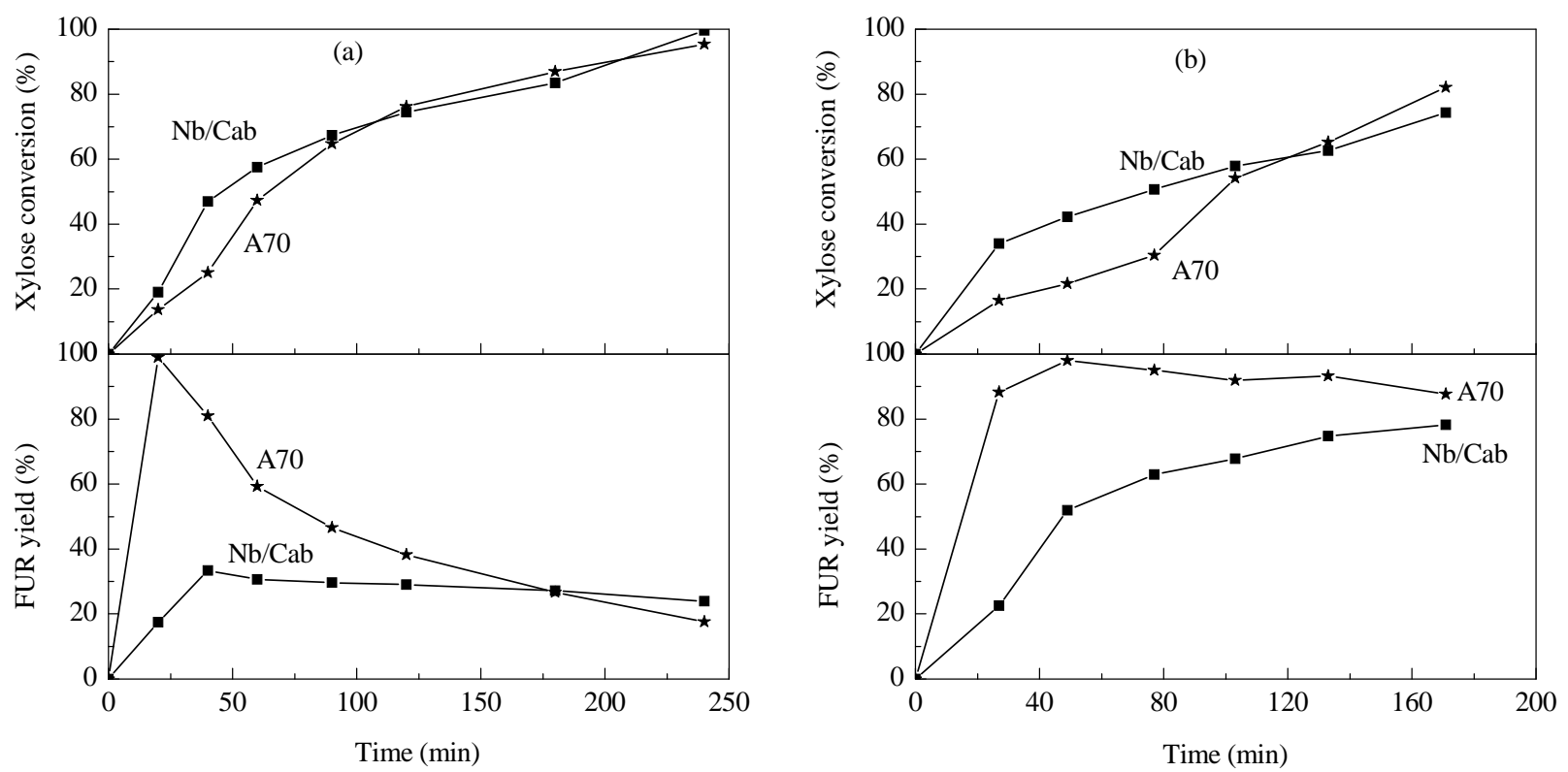

Fig. 2. Evolution of xylose conversion and FUR yield during batch reactor tests at $175{ }^{\circ} \mathrm{C}$ (a) and $\mathrm{N}_{2}$ stripping at $175^{\circ} \mathrm{C}$ using $150 \mathrm{ml} / \mathrm{min}$ of $\mathrm{N}_{2}$ at 800 kPa bar (absolute pressure) (b).

Lewis acid sites and converted at higher rates (Fig. 2(a)). Average TOF values (based on converted xylose) in the first $60 \mathrm{~min}$ were 4.28 and $0.06 \mathrm{mmol} /\left(\right.$ meq $\left.\mathrm{H}^{+} \cdot \min \right)$ for $\mathrm{Nb} / \mathrm{Cab}$ and $\mathrm{A} 70$, respectively. It has been reported in the literature [18] that Lewis sites are suppressed in water. However, if all the $\mathrm{Nb} / \mathrm{Cab}$ acid sites $(0.045 \mathrm{mmol} / \mathrm{g})$ were converted to Brönsted acid sites, the $\mathrm{Nb} / \mathrm{Cab}$ should show a lower activity than A70 (acidity of 2.55). Because both catalysts showed similar conversion rates, it was improbable that the Lewis sites were converted to Brönsted sites.

On the other hand, it is noteworthy that the presence of Lewis acid sites clearly changed the mechanism of FUR production from xylose as compared to that on Brönsted acid sites. The dehydration of xylose on Lewis acid sites occurs in two consecutive steps, as shown in Scheme 1(b). The presence of small amounts of xylulose in the HPLC analysis (not quantified)

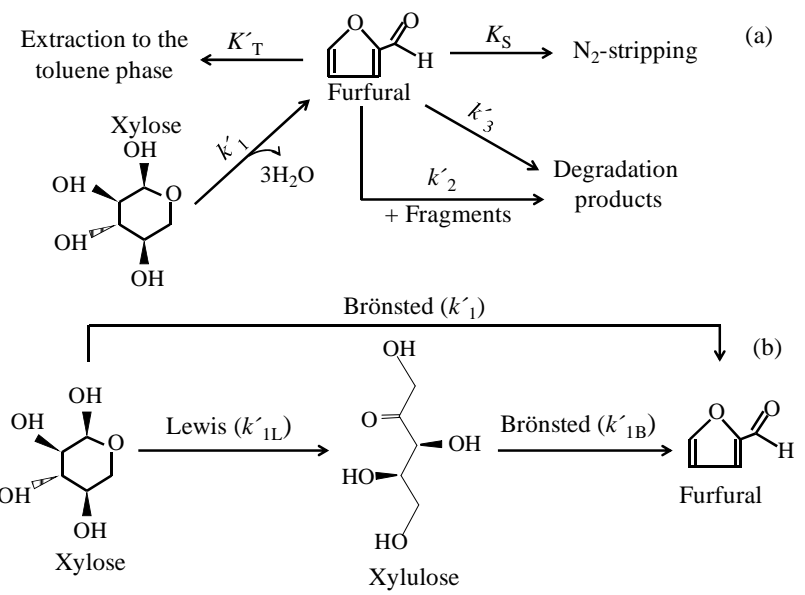

Scheme 1. (a) Kinetic and diffusion rate constants during xylose dehydration to furfural. (b) Mechanism and reaction pathways using Lewis and Brönsted acid catalysts in the xylose dehydration in water. suggested that xylose was first isomerized to xylulose and then further dehydrated to furfural. The reactions on $\mathrm{Nb} / \mathrm{Cab}$ were first catalyzed by the uncoordinated metal sites on $\mathrm{Nb}_{2} \mathrm{O}_{5}$, and the xylulose was dehydrated mainly by the $\mathrm{H}_{3} \mathrm{O}^{+}$in water. The direct conversion of xylose to furfural on a Brönsted acid (A70) requires a high activation energy, while the Lewis acids can lower this activation energy by 59\% [11]. The xylose dehydration activity is determined by the structural porosity [10] and type of acid site [19]. In our case, even if xylose diffusion in the pores might be limited by the porosity of the Cabosil support (diffusivity of $0.011 \mathrm{~cm}^{2} / \mathrm{s}$ ), this was offset by the presence of active Lewis sites that can convert xylose at a higher rate than A70.

On the other hand, the FUR yield differed greatly in the initial stages, reaching a maximum (99\%) at $14 \%$ xylose conversion for $\mathrm{A} 70$ (Fig. 2(a)). Because $\mathrm{H}_{3} \mathrm{O}^{+}$protons at $160{ }^{\circ} \mathrm{C}$ are not as strong an acid as the $\mathrm{SO}_{3} \mathrm{H}^{-}$groups on $\mathrm{A70}$, the xylulose intermediate on $\mathrm{Nb} / \mathrm{Cab}$ was dehydrated at a lower rate than when A70 was used, which opened a route to faster condensation reactions with FUR and thus a lower FUR yield than that obtained with A70 (Fig. 2(a)). The presence of $\mathrm{H}_{3} \mathrm{O}^{+}$is required to further dehydrate xylulose to furfural. At $160{ }^{\circ} \mathrm{C}$, water can self-ionize and form the $\mathrm{H}_{3} \mathrm{O}^{+}$hydronium form and be used as a Brönsted acid. These results clearly confirmed the different activities of the Lewis and Brönsted acid sites for the decomposition reactions. As shown in Table 1, the final FUR yield in water (Batch WT) did not exceed 25\%. Under biphasic water/toluene $(1: 1 \mathrm{v} / \mathrm{v})$ conditions (Batch WT), the FUR yields were increased by $\sim 40 \%$. In addition, the data were modeled to get a $K_{\text {T }}^{\prime}$ value (distribution coefficient between the aqueous and organic phases) of $4.6\left(\mathrm{~min} \cdot \mathrm{g}_{\mathrm{CAT}}\right)^{-1}$.

The presence of Lewis acid sites in solvents other than water would considerably change the reaction mechanism. Organic solvents such as DMSO gave lower yields than water but had higher acid site stability [10]. For an understanding of this, 
Table 1

Acid site stability and catalytic activity of $\mathrm{Nb} / \mathrm{Cab}$ and $\mathrm{A} 70$ at $175^{\circ} \mathrm{C}$ under batch reaction and $\mathrm{N}_{2}$ stripping conditions.

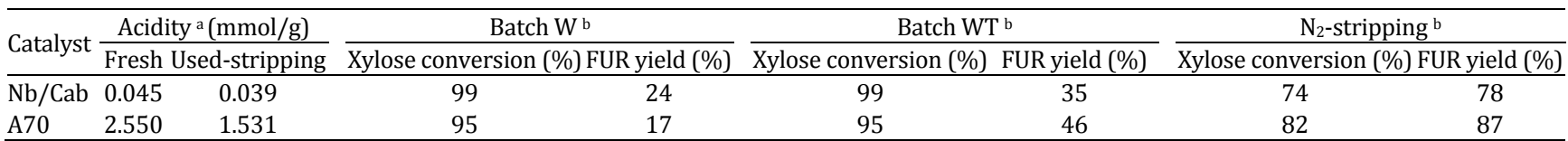

a Measured by $\mathrm{NH}_{3}-\mathrm{TPD}$ for $\mathrm{Nb} / \mathrm{Cab}$ and equilibration with $\mathrm{NaNO}_{3}$ and titration with $\mathrm{NaOH}$ for A70.

${ }^{\mathrm{b}}$ Test reactions performed with $1 \%$ of initial xylose load and $60 \mathrm{wt} \%$ of catalyst with respect to xylose load. The average standard deviation in the tests was $4 \%$.

the effect of water on the hydrolysis and Lewis acidity of $\mathrm{Nb}_{2} \mathrm{O}_{5}$ needs to be further studied. Catalysts that have optimized Lewis/Brönsted ratios and suitable textural properties are the best for studying xylose dehydration to FUR in water. Also, from a consideration of industrial application, different extraction configurations such as $\mathrm{N}_{2}$ stripping are a better approach than using extra solvents.

In order to model the experimental data, the kinetic constants (Scheme 1(a)) were simplified and split into three equations and iterated until the tolerance range specified $\left(10^{-9}\right)$ for the sum of least squares was reached. Xylose was directly dehydrated to furfural by A70, and it can also be further condensed with xylose intermediates or fragments. As shown in Scheme 1(b), the Lewis acid sites isomerized xylose to produce xylulose with a rate constant $k^{\prime} 1 \mathrm{~L}$, and this was then dehydrated to FUR catalyzed by a Brönsted site with a rate constant $k^{\prime} 1 \mathrm{~B}$. These constants were lumped as $k_{1}^{\prime}$ in the kinetic model, and $k^{\prime}{ }_{3}$ was obtained from the resinification reactions of FUR and catalyst. The constants showed slight differences for $k^{\prime} 1(6.8 \times$ $10^{-3}$ and $6.6 \times 10^{-3}$ (min. $\left.\mathrm{g}_{\mathrm{CAT}}\right)^{-1}$ for $\mathrm{Nb} / \mathrm{Cab}$ and A70, respectively), but significant differences for $k_{2}^{\prime}\left(6.4 \times 10^{-4}\right.$ and $3.1 \times$ $10^{-4} \mathrm{~L} /\left(\mathrm{min} \cdot \mathrm{g} \cdot \mathrm{gCAT}^{-1}\right.$. Obviously, the differences in the condensation reactions $\left(k_{2}^{\prime}\right)$ had the biggest influence on FUR yield reduction on $\mathrm{Nb} / \mathrm{Cab}$.

During the initial stage of the process operated with $\mathrm{N}_{2}$ stripping, xylose dehydration activity was faster with $\mathrm{Nb} / \mathrm{Cab}$ than with A70 (Fig. 2(b)). This gave higher FUR concentrations in the reactor (FURR). The stripped and condensed FUR (FURc) showed the same trend. $\mathrm{N}_{2}$ was a very efficient stripping agent and was able to achieve FURC/FUR ratios of 6-8. In the first 90 min, the condensate concentrations showed FUR concentration maxima for both catalysts. During $\mathrm{N}_{2}$ stripping, the liquid volume in the reactor decreased, so the catalysts required enough acid capacity to be able to convert xylose and thus achieve a constant xylose concentration profile. However, the molar conversion rate of xylose with $\mathrm{Nb} / \mathrm{Cab}$ was not as high as with A70, which was due to the blockage of the active sites by deposited humins. This decreased its dehydration activity by the end of the tests. This acid site blockage enhanced the occurrence of side reactions and reduced the FUR yield to 78\%. This phenomenon has been previously reported [20]. The tests performed in the absence of a catalyst gave lower FUR yield compared to the heterogeneously catalyzed systems. When the $\mathrm{Nb} / \mathrm{Cab}$ catalyst was deactivated by deposited humins, it showed a similar conversion to the non-catalyzed systems, and thus a lower FUR yield. As shown in the initial $\mathrm{N}_{2}$ stripping stages in Fig. 2(b), the Nb/Cab FUR yield was low due to the slow dehydration of xylulose to FUR. However, longer reaction periods favored the formation of FUR and $\mathrm{N}_{2}$ can be used to strip it and avoid its further degradation by condensation reactions (such as the ones reducing the FUR yield under the batch reactor conditions). On the other hand, the A70 acid amount was maintained higher than that of $\mathrm{Nb} / \mathrm{Cab}$ in the tests, and A70 showed a more constant xylose conversion rate. Moreover, due to the higher FUR yield from the Brönsted acid sites (shown in the batch reactor tests) and its higher acid amount, the A70 FUR yield was increased up to $87 \%$. The results clearly confirmed that the activity is dependent on the operational configuration. Moreover, clear FUR yield differences between the use of batch reaction and $\mathrm{N}_{2}$ stripping were observed.

The GC-MS analysis of the reactor liquid sample showed a broad range of degradation products from undesired reactions, such as pyruvaldehyde, dihydroxypropanone, and acetic acid. However, the stripped condensate sample showed a FUR selectivity of $98 \%$ for both catalysts, suggesting that $\mathrm{N}_{2}$ can effectively strip FUR from the reaction medium. From the modeled data, a $K_{\mathrm{S}}$ interphase separation value of $0.041 \mathrm{~L} / \mathrm{min}$ was estimated.

The regeneration of acid catalysts after xylose dehydration reactions is common [20]. In the $\mathrm{Nb} / \mathrm{Cab}$ case, the non-treated catalyst showed a considerably lower catalytic activity, suggesting that deposited coke should be removed from the surface. The acid amount of the used catalysts was also evaluated after coke oxidation using a thermal treatment at $550{ }^{\circ} \mathrm{C}$. As shown in Fig. 1(a), a reduction of adsorbed $\mathrm{NH}_{3}$ on the strong Lewis acid sites at $250-500{ }^{\circ} \mathrm{C}$ occurred, while the weaker acid site amounts were still the same. The overall desorbed $\mathrm{NH}_{3}$ amount showed small acid amount differences with respect to the fresh sample (Table 1). This observation proved the hydrothermal stability of the uncoordinated $\mathrm{Nb}_{2} \mathrm{O}_{5}$ even at high reaction temperatures. On the other hand, $40 \%$ of the sulfonic sites on the A70 sample were leached into the reaction medium. In spite of having less reaction acid site stability than $\mathrm{Nb} / \mathrm{Cab}$ (1.53 mmol/g), it showed higher accessibility and more acid amount than $\mathrm{Nb} / \mathrm{Cab}$. This allowed it to effectively dehydrate the xylose during all the $\mathrm{N}_{2}$ stripping tests. Amberlyst 70 is a commercial catalyst that can be used in non-aggressive solvents, such as dimethylsulfoxide. However, the presence of water in the reaction considerably reduces acid site stability. A new approach to enhance the hydrothermal stability is to modify the synthesis conditions. In a recent publication [20], an increase of the synthesis aging temperature was reported to induce higher sulfonic stability. This approach can also be applied to Amberlyst catalysts. 


\section{Graphical Abstract}

Chin. J. Catal., 2013, 34: 1402-1406 doi: 10.1016/S1872-2067(12)60599-3

\section{Dehydration of xylose to furfural using Lewis or Brönsted acid catalyst and $\mathrm{N}_{2}$ stripping}

Iker AGIRREZABAL-TELLERIA *, Cristina GARCÍA-SANCHO, Pedro MAIRELES-TORRES, Pedro Luis ARIAS

University of the Basque Country, Spain; University of Málaga, Spain

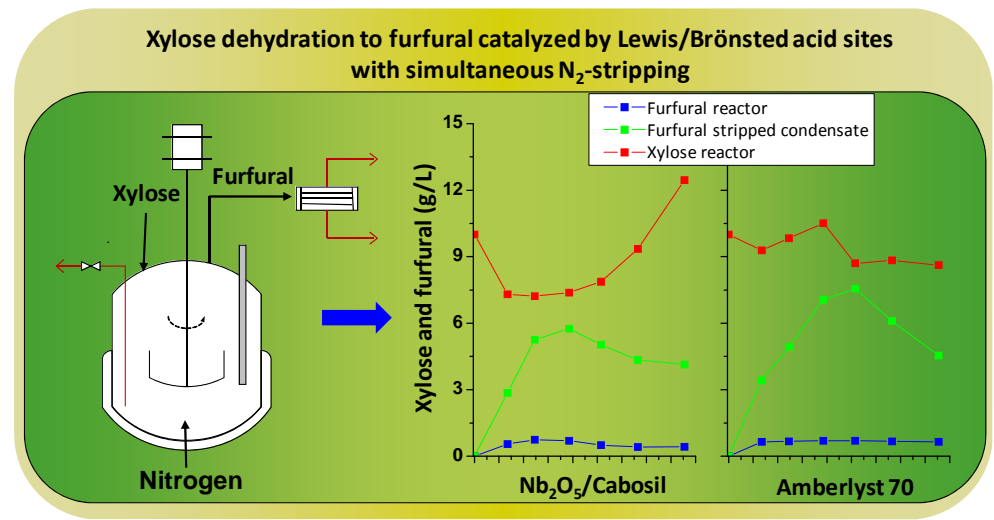

The present work studied the change of the xylose dehydration mechanism and furfural yield using Lewis $\left(\mathrm{Nb}_{2} \mathrm{O}_{5} / \mathrm{Cabosil}\right)$ or Brönsted (Amberlyst 70) acid catalysts in combination with simultaneous discontinuous $\mathrm{N}_{2}$-stripping.

\section{Conclusions}

Xylose dehydration activity showed differences on niobium pentoxide $\left(\mathrm{Nb}_{2} \mathrm{O}_{5} /\right.$ Cabosil) or sulfonic site (Amberlyst 70) catalysts. Lewis acid sites converted xylose at a higher rate than Brönsted acid sites, while strong Brönsted sites such as those on Amberlyst 70 gave a higher furfural yield. $\mathrm{N}_{2}$ stripping achieved better extraction efficiency than the use of toluene as a co-solvent. The use of $\mathrm{N}_{2}$ stripping with a solid heterogeneous catalyst has several environmental advantages with respect to the use of co-solvents, such as easier product-solvent separation, lower furfural dilution due to the use of non-condensable $\mathrm{N}_{2}$ and higher product purity. This advantage was obtained with both of the solid acid Brönsted or Lewis acid catalyst.

\section{Acknowledgements}

This work was supported by funds from the Spanish Ministerio de Economía y Competitividad (CTQ-2012-38204-C03-03 and ENE2009-12743-C04-03) and from the Gobierno Vasco (Programa de Formación de Personal Investigador del Departamento de Educación, Universidades e Investigación). The authors are also grateful to the Junta de Andalucía (P09-FQM-5070) for financial support.

\section{References}

[1] Karinen R, Vilonen K, Niemelä M. ChemSusChem, 2011, 4: 1002

[2] Antal M J Jr, Leesomboon T, Mok W S, Richards G N. Carbohydr Res, 1991, 217: 71

[3] Zeitsch K J. The Chemistry and Technology of Furfural and Its
Many By-Products. Amsterdam: Elsevier, 2000

[4] Dias A S, Lima S, Brandao P, Pillinger M, Rocha J, Valente A A. Catal Lett, 2006, 108: 179

[5] Dias A S, Pillinger M, Valente A A.J Catal, 2005, 229: 414

[6] Jeong G H, Kim E G, Kim S B, Park E D, Kim S W. Microporous Mesoporous Mater, 2011, 144: 134

[7] Dias A S, Lima S, Carriazo D, Rives V, Pillinger M, Valente A A. J Catal, 2006, 244: 230

[8] Moreau C, Durand R, Peyron D, Duhamet J, Rivalier P. Ind Crop Prod, 1998, 7: 95

[9] Kim S B, You S J, Kim Y T, Lee S, Lee H, Park K, Park E D. Korean J Chem Eng, 2011, 28: 710

[10] Agirrezabal-Telleria I, Requies J, Güemez M B, Arias P L. Appl Catal $B, 2012,115-116: 178$

[11] Lima S, Fernandes A, Antunes M M, Pillinger M, Ribeiro F, Valente A A. Catal Lett, 2010, 135: 41

[12] Weingarten R, Tompsett G A, Conner W C, Huber G W. J Catal, 2011, 279: 174

[13] Choudhary V, Pinar A B, Sandler S I, Vlachos D G, Lobo R F. ACS Catal, 2011, 1: 1724

[14] Zhang J H, Zhuang J P, Lin L, Liu S J, Zhang Z. Biomass Bioenergy, 2010, 39: 73

[15] Agirrezabal-Telleria I, Requies J, Güemez M B, Arias P L. Green Chem, 2012, 14: 3132

[16] García-Sancho C, Moreno-Tost R, Mérida-Robles J M, Santamaría-González J, Jiménez-López A, Maireles-Torres P. Appl Catal B, 2011, 108-109: 161

[17] Carniti P, Gervasini A, Biella S, Auroux A. Catal Today, 2006, 118: 373

[18] Corma A, García H. Chem Rev, 2003, 103: 4307

[19] Choudhary V, Sandler S I, Vlachos D G. ACS Catal, 2012, 2: 2022

[20] Agirrezabal-Telleria I, Requies J, Güemez M B, Arias P L. Appl Catal $B, 2012,115: 169$ 